\title{
Evaluating Capacity Building to Foster Climate Change Adaptation
}

\author{
Mary Ann Castle1, Norma Tan'1, James A. LaGro² \\ ${ }^{1}$ Cora Group, Inc., New York, NY, USA \\ ${ }^{2}$ Department of Urban and Regional Planning, University of Wisconsin-Madison, Madison, USA \\ Email: ntan@coragroupinc.com
}

Received 28 November 2014; accepted 6 March 2015; published 11 March 2015

Copyright (C) 2015 by authors and Scientific Research Publishing Inc.

This work is licensed under the Creative Commons Attribution International License (CC BY).

http://creativecommons.org/licenses/by/4.0/

(c) () Open Access

\section{Abstract}

This paper describes an evaluation of a capacity-building approach for promoting locally-driven climate change adaptation through local action. Using a leadership development strategy, a USbased NGO convened teams of dedicated sustainability practitioners from 15 localities for peer learning, team-building, and access to expert resources. The evaluation strengthened the NGO's theoretical framework and methods for understanding the capacity-building contribution of the intervention to climate change adaptation. It demonstrated the use of stakeholder data to test and refine assumptions about 1) how intended changes are expected to occur and 2) prioritizing the use of capacity-building resources. It also underscored the necessity of evaluation partnerships between the NGO and committed teams of change agents to sustain capacity-building effects while allowing data gathering over time to continuously refine the Theory of Change (ToC) and to guide local efforts to achieve climate change adaptation outcomes. The evaluation data showed that the initial ToC was not sufficiently robust to identify necessary conditions to be embedded in specific local situational contexts to increase the likelihood of success. The evaluators recommended enhancement of the ToC to consider team "readiness", while offering a logic model framework and capacity-building process metrics for progress and outcome tracking.

\section{Keywords}

Building Capacity, Climate Change Adaptation, Local Action

\section{Background \& Context}

\subsection{Awareness and Policy Action: The Current Landscape}

The United States' contribution per capita to global warming is the highest of any country in the world [1]. 
While China has surpassed the US as the world's biggest carbon emitter overall, the US is cumulatively responsible for almost $27 \%$ of all global carbon dioxide emissions [2]. A large body of evidence exists about the reality of global climate change and its environmental consequences-increased weather-related mortality, increased salinity of freshwater, radically altered crop yields and arable land, changed spatial distribution of infectious and respiratory disease, and the like [3]. In response, the Federal Environmental Protection Agency (EPA) has developed regulatory strategies to address some of these issues, e.g., improving fuel economy standards for cars [4] [5] and implementing new standards in 2015 to decrease methane emissions from natural gas and the fracking industry ${ }^{1}$. Despite President Obama's recent speech about climate change at the UN, powerful, well-financed corporate and conservative political forces with vested interests in fossil fuel have created and support "active denial" among large segments of the population about US vulnerability to the threats posed by climate change. The US Congress has often blocked legislation to reduce the US contribution to global warming. It is, therefore, urgent and necessary to support local community-based efforts for climate change adaptation, resilience, and mitigation in the US. Through effective evaluation and ways to support current adaptation practice, we can learn how best to adapt to climate change.

\subsection{Fostering Local Level Climate Change Adaptation, Mitigation and Resilience through a Capacity-Building Initiative}

This paper describes an evaluation of one US-based non-profit organization's (NGO) capacity-building process to promote locally-driven climate change adaptation policy and action. Using a civic development strategy, the NGO convened teams of dedicated sustainability practitioners through a series of meetings focused on knowledge exchange and team building for climate change adaptation - what we will here refer to as "adaptation planning sessions". These agents of change, drawn from 15 diverse cities and regions across the US, came together in teams to mitigate the causes and consequences of climate change within their local contexts. At the Adaptation Planning Sessions, local teams strengthened their relationships as a team and with other teams and faculty experts. The underlying premise was that through peer learning, team building, and access to the latest climate-related resources, participants would be better able to identify, promote, and implement promising local and regional climate change adaptation strategies.

\subsection{Evaluating Capacity-Building for Climate Change Adaptation, Mitigation and Resilience}

The NGO engaged the authors to conduct an external evaluation of the adaptation planning intervention. Broadly speaking, the NGO wished to test their Theory of Change (ToC) using a systematic evaluation methodology to determine whether, and how the adaptation planning session intervention contributed to locally intended policy and program outcomes. Underlying this request was the NGO's stated hope that the evaluation methodology could identify specific climate change adaptation indicators or measures of environmental impact that could be directly attributable to the adaptation planning session intervention.

\section{Capacity Building}

\subsection{What Is Capacity-Building?}

Capacity building is a process that builds upon and strengthens the existing capacities and potential of individuals, groups, organizations and collaborations to create change. Capacity building for sustainable climate change adaptation can encompass a host of behaviors and activities: providing exposure to new ideas, models and skills;

\footnotetext{
${ }^{1}$ The new fuel economy standards are probably the most significant regulatory action taken so far to reduce actual US GHG emissions. By the 2025 model year, all auto manufacturers selling cars and light-duty trucks in the US must meet an average fuel economy standard of 54.5 miles per gallon, nearly double today's standard. It requires the industry to capture methane and other emissions when drilling new wells. The EPA has also promulgated $\mathrm{CO}_{2}$ standards for new coal-fired power plants (the single largest source of GHG emissions). The standards for new plants amount to a de facto construction ban, because the pollution control technology necessary to meet the standards (carbon capture and sequestration) is not yet available on an industrial scale. So, no new coal power plants may be built in the US at this time. The EPA is currently working on standards for existing coal plants. All of these regulatory actions are taken within the existing framework of Sections 111 and 202 of the federal Clean Air Act. These provisions require EPA to regulate pollutants (including $\mathrm{CO}_{2}$ ) that are found to cause or significantly contribute to air pollution which may reasonably be anticipated to endanger public health or welfare. EPA made this "endangerment finding" with respect to $\mathrm{CO}_{2}$ and other GHGs in December 2009, following the landmark Supreme Court case Massachusetts $v$. EPA. http://www.epa.gov/airquality/oilandgas/pdfs/20120417fs.pdf
} 
fostering relationships and networking; effectively engaging in political dialogue; tailoring public communication messages; providing climate change leadership development skills and inspiration; and expanding resources. Good capacity-building practice requires a commitment to the multiple processes through which people can better influence the social forces that affect the change they want to create. It also requires a broad and long-term strategic vision that can guide concentrated activity on specific topics and contexts to produce capacity-building outcomes and, ultimately, intended environmental impact [3].

Climate change adaptation initiatives are challenging to evaluate [6]-[8]. Reasons include the enormity and complexity of the phenomenon and its far-ranging effects on natural and built environments and on human health and well-being. Beyond this, capacity building to enhance communities' ability to devise, organize and deliver effective climate change strategies is also difficult to evaluate. For example, programs may lack baseline data and have a long time lag between the climate change adaptation intervention and a measureable outcome [9] [10]. Or, many different interventions may be implemented without agreement on indicators or definitions of success. Climate change adaptation also requires collaboration across multiple sectors. And strategies used to support adaptation can vary widely in different local contexts, with different key leaders, and in different sectors. These factors make evaluation of capacity building for climate change adaptation especially challenging.

Consequently, capacity-building effort and their evaluation require 1) a deep understanding of strengths of community collaborations, 2) the degree of readiness to change by community leaders, policy-makers, businesses and other stakeholders, and 3) the social, economic, political and natural environments in which climate change adaptation is supposed to take place.

\subsection{Capacity-Building through Cross-Sector Teams, Knowledge Transfer, and Local Action Planning}

Fifteen teams from cities and regions throughout the US participated in the adaptation planning sessions. Teams were comprised of senior municipal and regional officials, civic and community leaders, private sector representatives, advocates, and other local stakeholders. At these in-person meetings, team members from different local communities translated their commitment to reducing climate pollution into effective plans of action. They did this by sharing promising practices; developing relationships with peers from other cities and regions and with leading climate change and adaptation national experts; and expanding their knowledge of how to access and use funding sources. The NGO's intervention, thus, gave them 1) easier access to the best available tools and resources and 2) the opportunity to build a collaborative network with local, regional, state and federal counterparts.

\subsection{Evaluating Capacity Building}

Most change agent teams were at early stages of formation at the time they attended an adaptation planning session. Consequently, the evaluation used existing and new data to develop a framework to delineate the steps required for the NGO's capacity-building effort to strengthen local climate change adaptation programming. Specifically, we:

- Reviewed project documentation and extant evaluative data, including NGO on-line resources;

- Reviewed the literature for good practice in climate change adaptation, including evaluation metrics for specific interventions;

- Assessed the NGO's Theory of Change (ToC);

- Developed a Logic Model Framework and demonstrated how to use it to operationalize the ToC by applying data from one case;

- Conducted an on-line survey of recent adaptation planning session participants (n = 292) from 15 cities/regions, with findings based on a response rate of $32 \%(n=94)$;

- Conducted in-depth interviews with change agents (25) from 3 (of 15) city/regional teams, i.e., Low Carbon Transportation, a Regional Climate Adaptation Planning Alliance, and Green Job initiatives.

\section{Testing the Theory of Change}

\subsection{Using Extant Data and Stakeholder Feedback to Enhance the Theory of Change}

The ToC postulated the contributory factors and processes by which the knowledge and skills gained by adapta- 
tion planning session participants would lead to climate change leadership in their local communities, subsequent to attending the adaptation planning sessions. Our evaluation focused on strengthening the NGO's theoretical framework and methodologies for understanding its capacity-building contribution to climate change adaptation interventions. Our goal was to better elucidate the processes by which participants-as individuals and in team formations - benefited from and applied what they learned at the adaptation planning sessions.

Specifically, we reviewed and refined the ToC as well as the tools and methods that the NGO had been using to track outcomes associated with their capacity-building interventions. What were the underlying assumptions of the ToC? Did the ToC delineate the necessary conditions for establishing effective local teams to meet climate change adaptation goals? Did it specify the factors associated with the intervention that might be shown, together or separately, to contribute to individual and/or team learning and subsequent efficacy? What metrics and indicators did the ToC suggest, if any, by which to track participants' learning and to evaluate the possible impact of participation on subsequent activity to foster resilience?

We also recommended the use of a logic model framework to operationalize the theory of change and to use evaluation data to test and refine assumptions with respect to how: 1) intended changes are expected to occur, and 2) capacity-building resources are to be prioritized.

A ToC that guides any initiative must initially be confirmed by stakeholders and then re-examined through evaluation. The NGO and teams expected us to develop a system of quantitative metrics to evaluate their climate change adaptation interventions and outcomes, believing this to be the best way to meet funder expectations. However, relying on quantitative metrics at the outset-without descriptive information on the dynamic socio-cultural context within which climate change adaptation is to occur-would fail to reveal dynamic power structures that teams themselves saw as among the most formidable barriers to successful climate change adaptation planning and implementation. Over-emphasis on metrics when teams were at beginning stages of readiness risked overriding the more critical need to engage people in making joint commitments to collaborative work toward common goals.

The evaluation data showed that the initial ToC was not sufficiently robust to identify necessary conditions for increasing the likelihood of adaptation planning session success. The findings, thus, led us to enhance the ToC to include consideration of the team's degree of "readiness" to work together when selecting teams for participation. Including team selection criteria in the ToC was important, considering its implications for both: 1 ) the design of the leadership development experience, and 2) follow-up after the adaptation planning sessions. The assessment of the ToC identified how a more robust theory would lead to an expansion in the NGO's capacity-building role and activities. It also underscored the necessity of evaluation partnerships between the NGO and committed teams to sustain capacity-building efforts. By sharing responsibility for both implementation and data-gathering, the NGO and local teams could most effectively facilitate leadership networks, hone climate change adaptation plans, and guide collaborative social action to achieve climate change adaptation outcomes while also demonstrating results.

\subsection{Developing a Logic Model Framework to Operationalize the Program Evaluation}

We developed a "logic map" to help the NGO conceptualize how the adaptation planning session can operationalize, and evaluate, its theory of change. This construct, viewed as a living tool that would evolve with the program and evaluation methods, would be useful to the NGO in communicating goals and strategies; coordinating data gathering, analysis and progress briefings; and reporting to, and by, stakeholders (including funders).

The logic map provides a structure to specify all assumptions underlying the program design. It defines resource "inputs" and implementation "outputs"-the unique program elements that are core to the program's value and efficacy. The logic map stabilizes stakeholders' understanding of the necessary components of the program, which must be recognizable even when implemented under varying conditions, times and situations. In each instance, the relative presence or absence of these elements provides the basis for determining the level of implementation of the intervention being evaluated.

We used one case study to illustrate how the logic map could serve as an evaluation framework for specifying, and then observing, outcomes over time. The logic map demonstrated the use of real data from a specific team's (observed and expected) outcomes. The segmentation of outcomes into short-, medium- and long-term indicators and outcome measures underscored the developmental nature of the capacity-building process. In this way, the logic map deepened understandings of necessary and sufficient conditions for effective capacity building. 


\subsection{Distinguishing Process vs. Climate Change Outcome Metrics}

We specified sample metrics drawn directly from the evaluation data in the climate change literature and from the US Environmental Protection Agency guidelines. This showed how different types of evidence of capacitybuilding at the local and regional levels could be mapped onto the NGO's theoretical framework. Case study and survey data revealed that adaptation planning session participants could describe the processes necessary to put their sustainability action plans into practice. Building on their input, we identified process benchmarks that could serve as common measures of the quality of partnerships [11]. Exhibit 1 illustrates partnership measures that emerged from the data. While not an exhaustive list of indicators, the exhibit shows the kinds of measures that teams generated to assess the quality of their collaborative capacity for meaningful social action.

\section{Exhibit 1. Process Indicators Related to Partnership Measures}

\section{Short-Term Measures}

- Identify and have all the "right" people who can make decisions and implement plans;

- Establish working relationship with mayor, city council, workforce development, public or private utility, appropriate city agencies, union, advocacy group, etc.;

- Establish planning sessions in departments/agencies for specific plans with strategies, suggested financing and inter-departmental discussions;

- Convene routine meetings;

- Establish and use on-going communication mechanisms;

- Write environment-specific plans;

- Obtain city council/mayoral approval for plans;

- Design and initiate advocacy strategies for legislative/city actions, e.g., tax referenda, court resolutions, city resolutions;

- Initiate legislative city actions completion of climate adaptation plan with strategies;

- Identify community stakeholders for priority action \& initiate public education;

- Develop initial set of outcome measures or indicators;

- Establish annual strategic meeting to review plans, goals, successes to dates, challenges and solutions.

\section{Mid-Term Measures}

- Complete all plans with strategies and suggested financing;

- Initiate community wide education and educational programs for students;

- Continue advocating with legislators and identify opportunities for integration;

- Integrate plans into general plan, emergency operations plan, other city planning \& decision making, e.g., include climate and energy strategies in transportation and land use plans;

- Plan and initiate research: e.g., risk analysis, appropriate mapping, inventories, assessments with intent to understand opportunities and challenges and to develop benchmarks;

- Identify longer term indicators;

- Establish data collection procedures.

\section{Longer-Term Measures}

- Continued citizen support and city approval of programs;

- Regional engagement in developing, initiating plans;

- Implement pilot projects in cities in the region;

- Continuation of strong inter-jurisdictional coordination;

- Integrate/coordinate city plans with regional plan and associated funding;

- Secure public-private partnerships for infrastructure investment.

\section{Outcomes and Lessons Learned from the Evaluation}

\subsection{Early Success Indicators}

After attending the adaptation planning session activities, almost two-thirds (61.7\%) of survey respondents reported having adjusted or created relevant policies and programs; promoted the importance of climate change issues more intensively; engaged in action planning with others; built teams to do the work of climate change 
adaptation. About three fourths (71.9\%) of respondents reported mobilizing their organizations to get results and to include more stakeholders in action planning (e.g., community organizations, advocates, union representatives, businesses). We are cautious in interpreting the self-reported survey data provided by the self-selected sample of respondents. However, it is consistent with feedback from interviews with adaptation planning session participants suggesting that some teams changed or enhanced their climate change adaptation planning processes directly as a result of information received from experts and peers at the adaptation planning sessions. Three examples follow:

Team X. Some Team X participants reported that they held a conference call with NYC on how to calculate the GHG baseline and benchmark measures. For example, the Transit Department began to collect data to measure improvements, e.g., increased transit ridership, transit trips per capita, air quality analysis, etc. After the adaptation planning sessions, there were important and new collaborations, such as between the Seaport and Expressway Authority. One of the ideas that emerged from this peer exchange was to analyze the flow of traffic and to consider a Stop and Stand project that might incentivize truck drivers to work off peak to minimize congestion. Thus, Team X adopted a strategy that had worked well for another city.

Team $\mathbf{Y}$ initiated an entry-level 18-month green job training program with a local trade school, businesses, and unions. Members from this team reported that prior to attending the adaptation planning sessions, they had the support of a strongly motivated senior city official with a commitment to developing Green Jobs for residents. This official, energized to take direct action by newly inspired team members who returned from the adaptation planning sessions, helped the team:

- Invest public funds of \$14 million to build retrofit jobs;

- Seek private investment;

- Design a pre-civil service certification program, adapting a model curriculum from a different team that attended the same adaptation planning session (452 completed training with 225 employed in retrofit projects in the city at the time of the evaluation);

- Pass an ordinance that all city buildings must be retrofitted (15 city buildings were retrofitted or almost completed at the time of the evaluation);

- Create more rigorous standards for privately owned buildings;

- Agree on, and set, long term targets for the city.

Team Y had included a representative from an advocacy organization. This was the first time the union and the department of water and power worked collaboratively with an outside entity to advance a climate change agenda. When individually interviewed, all team members reported that the advocate had been instrumental in creating a less defensive political environment and garnering public support. Their concern was how to scale up their weatherization and solar power programs by finding peers in other states/cities with successful models.

Team $\mathbf{Z}$ gained knowledge about low carbon transportation at the adaptation planning session. Afterwards, Team $\mathrm{Z}$ initiated a teleconference with another adaptation planning session team during which members learned how to calculate the greenhouse carbon or gas baseline and benchmark measures, e.g. their city transit department could collect data to measure improvements, such as increased transit ridership, transit trips per capita, air quality analysis and the like. They were, then, better able to create a strategy for designing better bus service through rider and community engagement.

\subsection{Social Influence}

Team members represented different sectors and cultural perspectives, professions, and organizational contexts; they also had varying access to decision-making power. The adaptation planning sessions provided a valuable opportunity for cross-sector teams to problem-solve on climate change adaptation issues that required working across individual and organizational boundaries to gain support for climate change adaptation plans. To be effective, each member had to build upon and develop their capacity to work collaboratively to produce results.

Collaboration is complex. Team members must be open to exchanging information and sharing resources, altering their activities, and enhancing one another's competencies for mutual benefit and a common purpose. Team members must build trust to be able to share risks and responsibilities, and to weather both failure and success [12]. In the US, as elsewhere, power to transform society is concentrated in elites. Often these are the very people who fail to support climate change adaptation, especially when their focus is on wealth creation rather than on human and environmental sustainability. The adaptation planning sessions provided team members 
the opportunity to be in a "safe place" to establish a common vision, mutual respect and a basis for trusting one another. This was a key aspect of the intervention: team members knew that they might have to take professional job risks to work collaboratively toward agreed upon climate change adaptation goals. Exhibit 2 lists some of the complex challenges described by teams.

\section{Exhibit 2. Challenges Faced by Change Agent Teams across Cities and Regions}

- Financial instability;

- Inter-jurisdictional complexity and variations;

- Scalability of projects;

- Climate change denial by decision makers/politicians;

- Lack of comprehensive, multiple sector team composition, including legislative authority;

- Need for Pre and Post adaptation planning session on-going capacity-building assistance;

- Need to build strong trust, respect and process for collaborative decision making, especially when at an early developmental stage.

\section{Recommendations}

The evaluation of the NGO's climate leadership development program showed a broad range of climate change adaptation strategies and approaches by different teams throughout the US. The findings highlighted the processes necessary for climate change leadership development and capacity-building to have a measurable impact. Reading across the findings for each team, a number of key lessons and priorities can be identified.

1) Conceptualizing a Theory of Change. Our evaluation assisted the NGO to re-conceptualize its ToC to more accurately portray the adaptation planning session intervention as a first step in a longer-term capacity-building process. Through our work, the NGO modified its initial desire to demonstrate to their funders a direct causal relationship between their climate leadership development strategy and specific environmental indicators (e.g. reduction in fossil fuel emissions). We helped the NGO to identify those elements of the adaptation planning session intervention that were especially critical for increasing the likelihood that sessions would result in teams returning to their home cities/regions and planning and implementing sustainable local climate change adaptation capacity. Using evidence from our evaluation, we helped the NGO enhance its ToC. We also re-focused the NGO on using process measures over time to assess: a) initial team readiness, b) composition of teams, c) level of expertise and follow-up support needed, and d) degree of success of different teams in meeting their specific climate change adaptation objectives over time. The approach we recommended (and illustrated using case study data), required ongoing collaboration between the NGO and teams to plan, implement, and also evaluate locally-specific teamwork outcomes.

2) Developing and Communicating a Local Theory of Change. Team members appeared to be unaware of the value of the NGO's Theory of Change in providing "the building blocks and relationships between them" that could lead to accomplishing the longer term climate change adaptation goals [8]. In the absence of a sustained approach to tracking collaborative team activity after the adaptation planning sessions, neither the NGO nor the teams would be able to offer convincing evidence of a connection between the session intervention and collaborative social action, much less show the relationship between such collaborative social action and measurable environmental change. Future adaptation planning sessions might focus more on educating participants on the benefits of developing a local ToC to facilitate persuasive communication with stakeholders. When stakeholders are asked to participate in concerted action, they naturally want, and need, to understand the rationale for adopting a particular change strategy. A logic model framework would also help stakeholders to appreciate the change strategy as a series of logical steps with resource and activity requirements which, when implemented, could result in desired climate change adaptation outcomes.

3) Requiring Pre-Adaptation Planning Session Activities. The evaluators recommended that the selection criteria for team participation in the adaptation planning sessions-as well as pre-session assessments and preparation - be more inclusive to achieve greater acceptance and impact. An important recommendation was to enhance the NGO's preparatory component by: a) recruiting based on team readiness, b) advising pre-session preparation, with emphasis on inclusive team membership and team meetings prior to participation in the adaptation planning sessions. The NGO could advise teams applying to attend an adaptation planning session on team composition, encouraging cross-sectoral, inter-jurisdictional representation in advance. This would go far 
in helping team members persuade their municipalities to recognize the importance of addressing climate change adaptation and including key stakeholders and decision-makers in the adaptation planning session. Those likely to be most affected by climate change adaptation changes as well as individuals and groups with power to generate, or obstruct, change (i.e. community residents, labor union representatives, advocates, workers) should be involved in initial team formation. Inclusive teams would have a "collaborative advantage" in moving forward to actualize their goals. The NGO could also assist teams to assess their readiness to do joint planning and to participate in knowledge sharing with teams from other localities. Preparatory work would also help the NGO work most effectively with selected teams to adapt promising strategies to fit their unique context.

4) Facilitating Knowledge Sharing across Networks. We encouraged the NGO to collect cross-discipline and cross-jurisdictional data to understand specific organizing needs of localities and regions. For example, the NGO might consider using network analysis to track the influence of its leadership development strategy on broad-based coalition-building to accomplish climate change adaptation aims. In line with this, we proposed process benchmarks by which to measure team commitment and effectiveness, hypothesizing that team sustainability (at least for some duration) would be a crucial intervening factor linking program participation and climate change adaptation actions and outcomes. By partnering with multiple teams, the NGO could collect and compare data across different climate change adaptation issues, action strategies, and team/situational contexts. Systematic evidence of "what works" could be gathered over the time necessary for teams' actions to have an effect on policy and implementation processes. Such data could serve to connect the NGO's intervention to climate change adaptation outcomes, perhaps even along "hard" measures of environmental impact.

5) Continuing Capacity-Building Activities Post-Session. The NGO’s capacity-building services have and can continue to assist municipalities and jurisdictions in the process of planning, developing, implementing and maintaining city- or region-wide climate change activities. Many, if not most, teams would need further help to strengthen their climate change adaptation plans and activities over an extended period of time. The NGO can make an important contribution by offering follow-up support to teams in their local environments. Such support would help teams stay together after the sessions, improving the likelihood of their garnering support for implementation of their climate change adaptation plans. Follow-up capacity-building assistance would strengthen specific teams' commitment and confidence in a common issue and approach. It would also give teams the opportunity to solidify joint goals and success criteria, while identifying implementation challenges likely to arise along the way. Teams would also have support for monitoring the attainment of their targeted outcomes. Finally, post-session technical assistance could further support the emergence of a network of local, regional and national level sustainability practitioners

6) Collaborative Fundraising. Funding, of course, is a significant consideration. The NGO, working with localities, might be able to coordinate fundraising efforts to attract support for follow-up technical assistance to several teams and/or to maximize the impact of smaller grants procured through currently available sources of support. Funders have an interest in seeing that their investment in convening teams leads to future results. The case could be made for resources to support a continued relationship between specific teams and the NGO to reinforce team building and application of knowledge in those localities showing readiness to engage as advocates with influential individuals and diverse stakeholder groups after the adaptation planning session. The NGO might also seek support to facilitate communication across localities. Funding for virtual conferencing would allow teams to help one another address challenges that they confront through in-depth information exchange and analysis, as well as sharing of solutions and success stories. With funding for continued knowledge exchange and targeted technical assistance, teams would be better able to overcome barriers that they face within their local contexts.

7) Incorporating Evaluation into Strategic Thinking for Future Planning. Evaluation designs should be integrated into climate change adaptation planning during early stages of development. The NGO can facilitate this by dedicating time at the adaptation planning session to evaluation. The NGO might also work with selected cities or regions to track progress, using both qualitative and quantitative metrics. Technical support might be prioritized for teams that agree to participate in outcome evaluation. These teams should receive support to document their progress using process benchmarks as well as implementation milestones. Ultimately, successful social action should result in measurable environmental change, taking a long term view. We also suggested, and partially illustrated, techniques that the NGO could use to track, enhance and evaluate its contribution to city and regional climate change efforts to promote environmental adaptation and sustainability over the long term.

Many respondents emphasized the need to conduct research and develop strong baseline information upon 
which to formulate their plans. Such data could provide information about current sustainability actions, policies, programs and/or interventions that are missing or needed, and the benefits, risks and costs of change. Assistance provided to team members with data collection and analysis would create opportunities to share and compare results, methods and lessons learned. Through this process, team members could identify and test effective solutions, sharing their evidence with other teams at future adaptation planning sessions.

\section{Summary and Conclusions}

Our evaluation aimed to guide this unique strategic leadership development effort toward greater impact. It did so by equipping the NGO with a realistic evaluation framework focused on tracking progress in building capacity - the necessary prerequisite to effect environmental change.

It also identified critical factors for successful implementation of climate change adaptation strategies, based on a review of secondary literature, post-session survey outreach to participants, as well as case study interviews with three selected teams. It also elicited and organized participants' thinking with respect to metrics planning.

The NGO's intervention posited that through participatory group learning, community leaders and change agents would be better able to identify, prioritize and implement appropriate climate change adaptation activities, drawing on newly acquired knowledge, models, and strategies. Our findings strongly suggested that the adaptation planning session intervention model enhanced the facilitative role of the NGO both before and after the adaptation planning sessions. Beyond this, the NGO can play a more direct role advising teams on their composition and preparation for the sessions, and on formal team selection criteria. These criteria should take inclusiveness of the team into account, with an emphasis on cross-sector representation (including outside agencies and advocates) and the support of influential stakeholders (ideally, with a strong "inside" champion on the team). Team readiness, as demonstrated through pre-convening team building and planning, also increases the likelihood of sustained team commitment and follow-up.

We also observed a great need for consistent and sustained support to teams after the adaptation planning session intervention. We, thus, strongly emphasized the need for ongoing collaboration between the NGO and teams, as well as the funding for follow-up technical assistance to teams. In line with this, we stressed collaborative follow-up to collect necessary and sufficient data on local capacity-building processes and outcomes to evaluate the contribution of the adaptation planning session intervention to climate change adaptation action and results. The adaptation planning sessions potentially created a network of "change agents" within and across cities and regions to further support climate change adaptation. Technical assistance to teams would permit routine, on-going cross-team communication and knowledge sharing, and effective messaging for specific populations on specific topics, such as how to successfully work with resistant legislators/politicians. Moreover, robust local efforts to disseminate the change strategy using a ToC and logic model framework could help promote stakeholder involvement in operationalizing the change strategy in complex, challenging environments.

As illustrated in this evaluation, agents of change in cities and regions across the US benefited from the capacity building offered by the NGO, using a climate change leadership development strategy. However, our findings highlighted a major challenge for the NGO-namely, to be able to procure and commit the resources necessary to facilitate long-term capacity-building and systematic evaluation. Additional funder and NGO investments toward locally appropriate technical assistance to increase and maximize the use and impact of limited resources would go far in helping local teams to meet their climate change adaptation goals.

\section{Acknowledgment}

The authors gratefully acknowledge Mr. Erik Laby, Project Associate, for his important contributions to the work described in this article.

\section{References}

[1] Scientific American ${ }^{\mathrm{TM}}$ (2012) China Greenhouse Gas Emissions Set to Rise Well Past US. http://www.scientificamerican.com/article/china-greenhouse-gas-emissions-rise-past-us/

[2] Boden, T.A., Marland, G. and Andres, R.J. (2013) Global, Regional, and National Fossil-Fuel $\mathrm{CO}_{2}$ Emissions. Carbon Dioxide Information Analysis Center, Oak Ridge National Laboratory, US Department of Energy, Oak Ridge, Tenn., USA.

[3] Eade, D. (1997) Capacity-Building. An Oxfam Publication, UK and Ireland. 
[4] Worldwatch.org. (2013) US Public Still Unconvinced on Climate Change. http://www.worldwatch.org/node/6300\#.U0WdRyO4-pY.gmail

[5] New York Times (2014) White House Unveils Plans to Cut Methane Emissions. New York Times, 27 March 2014, A12.

[6] Prowse, M. and Snilstveit, B. (2010) Impact Evaluation and Interventions to Address Climate Change: A Scoping Study. International Initiative for Impact Evaluation, Working Paper 7, 6.

[7] Ayers, J. and Forsyth, T. (2009) Community Based Adaptation to Climate Change: Strengthening Resilience through Development. Environment, 51, 22-31. http://dx.doi.org/10.3200/ENV.51.4.22-31 Institute of Development Studies (2008) Desk Review: Evaluation of Adaptation to Climate Change from a Development Perspective. Institute of Development Studies, UK.

[8] Bours, D., McGinn, C. and Pringle, P. (2014) Guidance Note 1: Twelve Reasons Why Climate Change Adaptation M\&E Is Challenging. UKCID: SeaChange. http://www.ukcip.org.uk/wordpress/wp-content/PDFs/MandE-Guidance-Note1.pdf

[9] Hedger, M.M., et al. (2008) Evaluation of Adaptation to Climate Change from a Development Perspective. Institute of Development Studies (IDS)/AEA Group. www.seachangeco.org/node/128

[10] Bours, D., McGinn, C. and Pringle, P. (2014) Guidance Note 3: Theory of Change Approach to Climate Change Adaptation Programming. UKCID: SeaChange. http://www.seachangecop.org/node/2933

[11] Environmental Protection Agency (EwPA) http://www.epa.gov/cleanpowerpla

[12] Himmelman, A.T. (1996) On the Theory and Practice of Transformational Collaboration; Form Social Service to Social Justice. In: Huxham, C., Ed., Creating Collaborative Advantage, Sage Publications, London, $18 f$. 